\title{
Toward a Systemic Notion of Information: Practical Consequences
}

\author{
Nagib Callaos and Belkis Callaos \\ Universidad Simon Bolivar, Venezuela
}

\author{
ncallaos@usb.ve bsanchez@usb.ve
}

\begin{abstract}
Our main purpose in this paper is to start a process of a systemic definition of the notion of information and to provide some initial practical consequences of it. We will try to do that providing: 1) a conceptual definition, following Ackoff's (1962) description and method of such a kind of definition, and 2) following Peirce's (1931-5,1958) conception of "meaning", where the practical consequences should be included. To our knowledge, no attempt has been done up to the present neither to find a Peircean meaning to the notion of information, nor to start a process of describing a systemic notion of information. Consequently, we will try to integrate the different definitions made on information. But to integrate we should first differentiate what is to be integrated. Thus, we will typify information conceptions in subjective and objective, providing brief description and analysis of each type, integrating them in the context of a systemic notion of information, and drawing the respective pragmatic consequences, as required by Peirce, for any meaning description, and by a pragmatic-teleological systemic epistemology (Churchmann, 1971)
\end{abstract}

Keywords: Information Meaning, Pragmatic Meaning, Systemic Definition, Information Systems, Informing Sciences.

\section{Introduction}

The meaning of "information systems" has been growing in diversity and complexity. Several authors pointed out this fact, described the phenomena and tried to bring some order to the perceived chaos in the field. Cohen (1997, 1999, 2000), for example, after describing the attacks on the Information Systems (IS) field, for "its lack of tradition and focus" and the "misunderstandings of the nature of Information Systems", examines "the limitations of existing frameworks for defining IS" and re-conceptualizes Information Systems and tries "to demonstrate that it has evolved to be part on an emerging discipline of fields, Informing Science" (Cohen, 2000).

Our objective in this paper is to participate in the process of conceptualization and re-conceptualization required in the area of Information Systems and in Cohen's proposed Informing Science. We will try to do that making a first step in the description of a systemic notion of information, by identifying, first, the meaning of information. We are using the word "meaning" in its pragmatic sense, i.e. in the sense Peirce formulated when he pointed out that " in order

Material published as part of this proceedings, either on-line or in print, is copyrighted by the author with permission granted to the publisher of Informing Science for this printing. Permission to make digital or paper copy of part or all of these works for personal or classroom use is granted without fee provided that the copies are not made or distributed for profit or commercial advantage AND that copies 1) bear this notice in full and 2) give the full citation on the first page. It is permissible to abstract these works so long as credit is given. To copy in all other cases or to republish or to post on a server or to redistribute to lists requires specific permission from the author. to ascertain the meaning of an intellectual conception one should consider what practical consequences might conceivably result by necessity from the truth of that conception; and the sum of these consequences will constitute the entire meaning of the conception." (Peirce, 5.9.) When Peirce talks about "consequences", he is referring to the relation (consequentia) between the pair of antecedent and consequent, not just about the consequent (consequens) So, accordingly, we will try to analyze the antecedents, by means of Ackoff's approach to conceptual definitions (1962), then we will try to relate them to the respective consequents. In this way the meaning we will looking for the term "information" will be both: its conceptual definition, as well as its respective practical consequences in the field of Information Systems and Informing Sciences. This will provide the input for establishing the direction of a systemic meaning of the notion of information.

The term "information" has been widely and increasingly used, but not always with a clear idea about its meaning. As Dretske (1981) and Lewis (1991) pointed out, few books concerning information actually define it clearly. And, Mingers (1997) adds: "Information systems could not exist without information and yet there is no secure agreement over what information actually is." (p. 73) The word "information" is one of the most used, and very abused, one. Different scientific disciplines and engineering fields provide diverse meanings to the word, which is becoming the umbrella of divergent, and sometimes dissimilar and incoherent homonyms. When concepts are not 
clear, the use of homonyms might be intellectually and pragmatically dangerous. We will try, here, to make an initial step, attempting first a conceptual definition. We are using "conceptual definition" with the meaning Ackoff (1962) described for it, and with the role he ascribed to it as a first step in both: scientific inquiry and systems analysis and synthesis. We will also follow the method suggested by Ackoff, but with the space restrictions of this paper.

We can find, in the last years, a growing number of research studies directed to establish the meaning of "information." Some of these research studies will be cited below. In spite of the plurality of the approaches followed, we did not find studies oriented by Peirce's definition of "meaning" as applied to the concept "information", let alone studies where the defining process has the objective of finding practical consequences in the area of information systems development. We have no knowledge, neither, to any kind of efforts made for the elaboration of a systemic notion of information. In our opinion, these two lacking aspects in the literature are very important both: from the intellectual and scientific perspective, as well as from the pragmatic one.

\section{The Subjective Conception of Information}

Information has been frequently defined as "interpreted data" and, as such, the same data might cause different interpretations. Different persons might associate different meanings to the same data. This kind of definition is frequently found in Information Systems textbooks, especially those oriented to Information Systems Development and Managerial Information Systems (MIS). Data in a MIS should provide some meaning to some manager in order to fulfill its raison d'être, its reason or justification of existence. An interpretation is, by its own nature, subjective, i.e. related to a subject, a "mind, ego, or agent of whatever sort that sustains or assumes the form of thought or consciousness." (Merriam-Webster, 1999) Consequently, it is easy to conclude that according to this kind of definition there is no IS without a subjective sub-system, i.e. any IS should have at least two subsystems: an objective (mechanical and/or electronic data processing sub-system) and a subjective one (biological/human data/information processing: a user, a manager, etc)

Some authors are a little bit more explicit and precise in their definition of information. They describe it as "data plus meaning" or "meaningful data" (Checkland and Scholes, 1990; Mingers, 1997). The term "data" etymologically means "things given or granted." Data are the plural of "datum," a Latin term, which is the past participle of "dare" (to give). On the other hand, the term "mean" derive from the Middle English "menen," akin to Old High German term "meinen," i.e. "to have in mind." (MerriamWebster, 1999) This etymology of the term has been mostly maintained to the present time. So, "to mean" is defined as "to have in mind as a purpose" and as "to serve or to intend to convey, show or indicate; to signify" (Merriam-Webster, 1999) "To signify" is the Latin rooted term equivalent to the Old High German rooted "to mean." Consequently, the term "meaning" has been defined as "the thing one intends to convey especially by language" or "the thing that is conveyed especially by language"; and "meaningful" is defined as "having a meaning or purpose" "full of meaning" "significant"(Merriam-Webster, 1999). Consequently, "information," as "meaningful data," would be defined as "significant data", "data full of meaning", "data having a meaning or purpose," and as "data plus meaning" would be defined as "data plus significance," "data plus the thing conveyed by it in the mind." Then, it is easy to make the same conclusion we did above: since information is something that should be in the mind of someone, information is always in a person, in a subject, i.e. it is subjective. The concept of "meaning" has been researched and studied by several authors (see, for example, classic Ogden and Richard's classic The Meaning of Meaning, 1989), in a very detailed, analytical and profound way. Elsewhere (Callaos 1995a), trying to make a systemic definition of "meaning" and to find the meaning of "definition", we made a thorough description of these researches and studies, and one of our conclusions was the one we briefly made here.

A similar conclusion might be derived from the etymology of the word "information." "Inform" originated from the Middle English term "enforme", derived from the Middle French term "enformer", which evolved from the Latin term "informare." (Merriam-Webster, 1999). This Latin term means: "shape, form an idea of" (Hoad, 1993). To form an idea is always in the mind of a person, of a subject. On the other hand, "informare" is a composite of "in-" and "form." The last term means "shape, mold" The term "in-" "is used in combination mainly with verbs and their derivatives, with the senses of 'in, into, within'." (Hoad, 1993) Accordingly, "to inform" would mean "to form in", "to form into", "to form within" a person, a subject, or as Boland (1987, referenced by Cohen, 2000) concluded "...information is the inward-forming of a person that result from the engagement with data." The conclusion we made, from the etymological analysis of the term converge with the conclusions made by several authors by means of other kind of analysis. Dervin (1983), for example, points out that "Since it is assumed that all information producing is internally guided and since it is generally accepted that 


\section{Toward a Systemic Notion of Information: Practical Consequences}

all human observing is constrained, sense-making further assumes that all information is subjective (p. 4, Dervin emphasis). Information is understood not as a thing but as a construction (Dervin, 1981) She recognizes that there is objective information, but place it in quotation marks as “ 'some information' out there, external to human beings, but created by them." So, what she is saying is that any information originates in a subjective source and is transformed by other subjective processes, performed by the receiver.

What might be called 'objective information' is a representation of the real information, which always is a subjective one in its origin and essence (we will use this extension of the term's meaning later, in the context of our systemic notion of information). Neill (1992) makes the same kind of emphasis: "knowledge representation - he says - are not knowledge but rather representation of knowledge" (p. 34). Therefore, the conclusion is evident: information is generated inside the mind of a person, a subject. It is not an objective entity independent of any person. It is dependent on the person where it is generated by the data stimulus, as well as on his/her individual experience. This is a very important conclusion, that many authors of IS books, or papers, do not seem to be taking into account.

Koshen (1983) defined information as "decision-relevant data"(p. 278), which makes of it something requiring a special kind of subjectivity, a strict subjectivity that exclude the possibility of inter- or trans-subjectivity, due to the personal nature of "decision" and "relevant decision." Decisions are always subjective, and relevancy is always related to a given subject.

Consequently, we can observe that for some authors subjective reception of the data are a necessary condition for in-formation generation, but it is not a sufficient one. To receive data related to my first name does not generate information in me. To have the data related to the first name of a person I just met, does generate in-formation "in" me, especially if I have some kind of interest in such a person and in knowing his or her first name. So, not any kind of data in any person generates in-formation in him, or in her. The received data should generate a new idea, or a relevant cognitive content, in the receiving subject, in order to produce in-formation in his or her mind. Consequently, it is important to find out the additional conditions that data should comply with, in order to be informative.

Floridi (1999) provides us with an essential condition. He points out that information is provided when data answer an explicit or an implicit question made by the data receptor. "To become informative for an intelligent being a datum must be functionally associated with a relevant query." (Floridi, 1999, p.106) Accordingly, data, to be informative, should be associated with a relevant question, and
- in Floridi's terms - information consists of "datum and relevant question...Computers certainly treats and 'understand' data; it is controversial whether there is a reasonable sense in which they can be said to understand information." (Emphasis is ours) Computers might process data, but information can be processed just by the computer user, the individual, the person, the subject. To Floridi (1999) "A datum is anything that makes a difference: a light in the dark, a black dot in a white page, a 1 opposed to 0 , a sound in a silence...A datum can be defined as an answer without question: 12 is a sign that makes a difference, but it is not yet informative, for it could be the number of astrological signs, the size of a pair of shoes or a name of a bus route in London. We do not know which...12 become informative when once we know it is the answer to the question 'how many apostles were there?"' (Floridi, 1999; p.106)

As a way of doing an additional step in our attempt to pinpoint the nature of information and data, as well as the contrast between both concepts, it is good to try to integrate our conclusions above with Floridi's erotetical definition (i.e. definition made according the logic of question and answers, the erotetic logic) Doing so, we can draw the following conclusions:

- A datum is a "given" thing, not any "given" thing, but the one that makes a difference. So, the genre of datum is "to be given" and the characteristic that makes it specific, specie in such a genre, is that it should makes a difference.

- Information is a cognitive content, not any cognitive content, but the one related to the association of data and a relevant question, be it implicit or explicit. So, the genre of information is cognitive content and the characteristic that makes it specific, specie in such a genre, is the relevant question that the data answer.

- Data and information are two sides of the same coin: Datum is the objective side of the coin and information is its subjective side. This relation might be seen as analogous to the relation between the signifier (the objective/material side of a sign) and the signified (its subjective/mental side), in semiological terms.

Having made these consequences, from the meaning given above, it is good now to be a little more analytic, focusing a little in the term "form" (meaning etymologically: "shape, mold,") from where we got the semantic meaning that is of our interest in this paper, i.e. "the shape and structure of something as distinguished from its material"(Merriam-Webster, 1999). The notion of form has a long philosophical, logical and methodological history, and this is not the place to cover it, not even succinctly. So, we 
Nagib Callaos and Belkis Callaos

will draw just those meanings related to our purpose in this paper. Greek philosophers used the term "form" to distinguish between external and internal figure. So, from its very beginning form was related to a mental figure, or to the non-tangible figure of an object. The Greek term

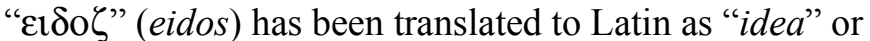
"forma", i.e. "idea" and "form" were taken as synonyms in order to translate eidos. This sense of the word was very used by Plato. Aristotle introduced several aspects that will be important for us below. He expanded the meaning of "form" as to include the objective world in its domain. $\mathrm{He}$ worked with the pair matter/form in an analogous way to what later would be the pair content/form. An object has matter and form, tangible and intangible presence. He also conceived four causes: the material, the formal, the efficient and the final. The final cause (the purpose) determine the idea, the form, according which the efficient cause act on the material cause in order to produce what is sought for. In this way, the form, which can be a mental idea first, might generate its objective counterpart, and vice versa. This conception is very important in our attempt to transcend the implicit definitional war that is beginning to exist among theorists in the information area, and to relate, cohesively the subjective stand with the objective one, and to try to hypothesize about a systemic integrative meaning of information, which will be done below.

\section{The Concept of Information as an Objective Form or Order}

Lately, an increasing number of authors are showing an objectivist bias in their conception of the notion of "information". Shannon's definition of information is at the roots of this perspective, and information technologies authors provided its strong impulse. Shannon, in his 1938 paper, "A Mathematical Theory of Communication," proposed the use of binary digits for coding information. His "concern was with the transport of information - specifically, how much information could be moved from sender to receiver via a noisy channel." (stonier, 1997) To do so, he gave a mathematical definition of "information", relating it to a signal probability. In this context, the "quantity of information" maintains an inverse relation to signal probability. Focusing on this idea, Shannon defined "information" as minus the logarithm of the signal probability (Cover and Thomas, 1991), i.e.

$$
\text { Information }=-\log p_{i}
$$

where $p_{i}$ is the probability of signal $i$.

Consequently, the information expected value of an $n$ states system would be:

$$
\text { Information }=\mathrm{I}=-\sum p_{i} \log p_{i}=- \text { Entropy }
$$

For a two states system, its information expected value will be:

$$
\text { I }(\text { for } 2 \text { states system })=-p_{1} \log p_{1}-p_{2} \log p_{2}
$$

where $p_{1}+p_{2}=1$

If we take the derivative of this function in order to identify its minimum values, we will find that this value is given for $p_{1}=p_{2}=1 / 2$. So, the minimum information will be:

$$
\begin{gathered}
I_{\min }(\text { for } 2 \text { states systems })= \\
-1 / 2 \log 1 / 2-1 / 2 \log 1 / 2=-\log 1 / 2=\log 2
\end{gathered}
$$

And, if the logarithmic base is 2 , then $I=\log _{2} 2=1$, which is the definition of "bit", i.e. a bit is the minimum information that a systems of two states can provide, or the information that could be provided by a 2 states systems with maximum entropy.

This mathematical definition of information opened the doors for many scientific and technological advances. A huge and tremendously promising field is emerging with names as "Quantum Information," "quantum computing," "Quantum cryptography," etc. as a result of this definition that objectified information (see, for example, Siegfried, 2000 , for a popularizing description of this new area). In this emerging field, traditional information theory (based on Shannon's) is being combined with quantum mechanics in order to formulate a new Quantum Information Theory. But, Shannon's information theory also opened the door for a lot of ab-use of the word "information" and a dangerous twist of the related concept. (We are using the word "abuse" instead of "abuse" in order to emphasize the etymological meaning of the word) Shannon made a mathematical definition of "information" in order to measure it, in the context of electronic communication systems. Consequently, the following should be kept in mind:

- Shannon did a mathematical definition, not a conceptual one. Many authors emphasized the huge difference between these two definitions. Leibniz, for example, distinguished emphatically between real definitions and mathematical or nominal ones. The former "show clearly that the thing is possible, while the latter do not," the former are arbitrary, while the later do not. (thoughts on knowledge, truth and Ideas; G., 4, 424-5; D., p.30, referred in F. Colpeston, 1985, Vol. IV, p.276) Shannon's definition is arbitrary. What is the justification of the logarithmic function if not its mathematical suitability? This arbitrariness does no harm at all when we use it to measure a propriety or a quality of a thing. 


\section{Toward a Systemic Notion of Information: Practical Consequences}

But, to try to equate it to the real thing, to its nature and essence is highly dangerous, because it is very misleading.

- We cannot confuse a measure of a thing with the thing measured, let alone to confuse the metric, with the thing measured by it. We should not confuse the centigrade scale we use to measure the temperature with the temperature. Similarly, we should not confuse Shannon's metric, or the measure we achieve with it, with the concept of information. Furthermore, if the metric were measuring one of the properties, what would happen with the others, if they exist? We should not confuse a part with the whole to which it belongs. We cannot define a whole by means of one of its parts. Metonyms are good means for poetic or metaphorical expressions, but they could be dangerous for conceptual reasoning and communications.

- Many authors made severe critics to Shannon's definition of information, although "Shannon never claimed to have developed a theory of information. Instead Shannon considered his contribution to have been a theory of communication - i.e. a theory of information transport" (Stonier, 1997, p. 13, emphasis made by him). Cherry (1978) pointed out "the formula derived by Shannon for the average information contained in a long series of symbols is really a measure of the statistical rarity or 'surprise value' of a course of message signs. This is hardly a true measure of information content of a message." (Referred in Stonier, 1997, p.13) Bar-Hillel $(1955,1964)$ pointed out, Shannon's Information Theory would be better called a "Theory of Signal Transmission" as this is its subject matter. But, this is not the case and we think that the probability to reverse this situation is very slim. So, we propose to extend the original subjective meaning given above in order to include Shannon's definition, to extend Shannon's as to include the subjective perspective, or to do both extensions in order to converge in a Systemic Information Theory.

Shannon's Theory provided the grounds for a strong support to the objectivist position, where information is conceived as completely independent from their senders and receivers, and as a neutral reflection of real world structure or order. The identification of information with negative entropy, or negentropy, made by Shannon, gave the foundation of the increasing emphasis in the objectivist conception of information. Shannon found out that his equation was isomorphic with Boltzmann's equation of entropy. So, equating both of them, he equalized information to negative entropy. This made some sense, because since entropy is conceived as disorder, negative entropy and information (its mathematical isomorphic) might be both seen as order. Then, anyone who conceives an independent order in the Universe would accept that information, its 'synonym', is independent, from any subject. This explains the increasing number of authors endorsing the objectivist position. Some of them are radical objectivists; they have what it might be named as physicist conception of information. They equate the ubiquity of information in the physical world to energy and matter. Let us take just one example. Stonier (1997) - for example - asserts "the description of all physical systems entails not only the parameters which define the amount of matter and energy, but also the quantity of information. Furthermore, any changes in the systems must take into account not only changes in matter and energy, but also changes in the information content of the system." (p. 12, the emphasis is ours) "Just as we ascribe to matter to mass encounter in our universe, and to energy the heat - Stonier continues stressing - so must we ascribe to information the organization (or lack of it) which we encounter in all systems." (Emphasis made by Stonier). The idea - Stonier affirms - that information is an intrinsic component of all physical systems requires a reevaluation of the law of physics." (p. 12, emphasis is ours)

In the other hand, in the information technologies world, the locution "information processing" is frequently used indistinctly to "data processing." At the beginning of computing the locution most used, to refer to computer systems, was "Electronic Data Processing" (EDP), which was the right term to use. But after the appearance of the expression "Management Information Systems" (MIS), which is also a very adequate one because it refers to managerial, hence human, information, an increasing number of vendors, first, and then consultant and academics, started using "information processing" as synonym and instead of "data processing." The original cause of this switch in the locutions' use was surely due to marketing variables. The word "information" sounded more actual that the term "data", because the prestige of MIS then. This fact was reinforced by the explicit, or implicit, semantic effort to differentiate the software in the realm of data bases, data base management systems (DBMS) and data base servers, from applications software, and middleware. Data processing in the latter are called frequently "information processing," and the expression "data processing" is usually used in the DBMS and data server realm. This way of using the word "information" contrasts and is in conflict with its meaning in the realm of MIS, DSS (Decision Support Systems) and EIS (Executive Information Systems). In MIS/DSS/EIS realm, information is always subjective, but in non-applications software and middleware (NAS/MW), realm information is always objective. The confusion be- 
tween these two senses of the term is very dangerous, both: intellectually and pragmatically. Below we will draw some conclusions in regards to this alert.

\section{Toward a Systemic Notion of Information}

Subjectivist and objectivist conceptions of information are definitely opposite, but we propose that they are not contradictory as they are, explicitly or implicitly, supposed to be. In our opinion they are polar opposites. To be a contradictory opposition "subjective" should be equated to "non-objective" and "objective" to non-subjective", but this is not necessarily the case. The Systems Approach dissolves the objective-subjective dichotomy and focus on what relates and communicates them, i.e. what is common to both of them. Rationalism Vs. Empiricism is not a valid conflict any more. For Churchman (1971) the Systems Approach focuses on the subject's action on the object. His pragmatic teleological truth is based, not on the subject and his/her reasoning, not in the object and the empirical data received from it, but on the action of the subject on the object. As long as the action achieves its objectives, the action will be a truthful one. Elsewhere (Callaos, 1995b), we noticed that the background of this epistemological position is placing truth in what relates the subject to the object, what makes them a system, not a set. In the "Rationalism Vs. Empiricism" conflict each epistemological position focus and place the truth in one part of the system subject-object. Churchman's Systems Approach places it in a relation between them. We explained with details (Callaos, 1995b) the necessity in going further in the direction established by Churchman, noticing that there is an "action" of the objective world on the subject, by means of his or her empirical sensations and then his/her perceptions of the world. Hence, we proposed a distributive notion of truth, located not just in the Subject (Rationalism), not just in the Object (Empiricism), not just in the action of the subject on the object (pragmatism), (i.e. one of the relations that relates them), but we showed that the truth is the whole system: In both of its parts and in both of its relations, i.e. distributed in the subject, the object and in what relates them (perception and action). This systemic notion of truth, where subject and object are no more in contradiction but in polar opposition, complementing each other in a creative tension process, might also be used to relate systemically the objective and the subjective notions of information.

A systemic notion of information would place it not just in the subject, or in the object, but in both of them and in what relates them. Objective and subjective information relates to each other as north and south poles, as masculine and feminine categories. They do not exclude each other, because they do not contradict each other. They require each other. They are dynamically related in a neverending creative tension process, where they feedback and feedforward reciprocally by means of the relations of perception and action. The subject perceives order and organization in the object, receiving some information from it (with its respective noise), then the subject acts on this order, 1)by means of his/her experience/knowledge/rational filters, and 2)by re-ordering it according to his/her objectives. Then the subject acts on the objective world by means of his/her verbal and written language, and participating in the creation of knowledge, social organizations and the technological world. In doing so, he/she sends information to the objective and inter- and transpersonal worlds, augmenting and/or modifying the information in them. These worlds will act back on the subject, through his/her empirical sensations/perceptions, re-initiating the cycle briefly described. These cycles, with their respective feedback and feedforward loops, has been going and will go through human history, in a dynamic creative tension process, where the subject re-creates and is re-created by his objective world, by means of re-receiving and resending information. It is an invalid question to ask about the origin of the information, whether it is objective or subjective in its origins. This kind of questions is consequence of a lineal thinking. It is not legitimate and makes no sense in a non-lineal thinking or a non-lineal dynamic process or systems, which is the essence of our systemic definition of information.

There have been some extensions made in both: objective and subjective conceptions of information, that would support our attempt into integrating - although not unifying both positions in a systemic notion. The most important to our purpose here are the following:

- Some authors suggested that Shannon's equation would also be effective in measuring subjective information, if we replace the objective probability in it by a subjective one. In this way subjective information could be measured as minus logarithm of the subjective probability that a given subject has in regards to the appearance of given signal or a sign. This extension had a very good consequence: it showed the Information Technology community how wrong it is to confuse data with information. A signal or a datum is mathematically the independent variable in Shannon's equation and information is the dependent variable. Both notions have a very precise mathematical distinction, and to confuse, or identify them, is mathematically nonsense. This extension served as the basis of many experiments in subjective information, but it measures just the uncertainty aspect, or - as we said before - the statistical rarity of the signal. Consequently, some authors, like Ackoff ${ }_{111}$ 


\section{Toward a Systemic Notion of Information: Practical Consequences}

quently, some authors, like Ackoff, proposed to name this kind of information "rarity information," in order to differentiate it from what has been called "semantic," "pragmatic," and "social" information. So, Shannon equation could be used to, at least, measure some kind of subjective information, or one aspect of it. This supports a partial integration of both positions.

- In the other direction, some authors in the subjective perspective accepted that even, information is always generated by a subject, it could be transmitted to an object. Although, some of these authors would say that what has been transmitted is not the real information, but some kind of it, or as Dervin (1983), mentioned above, named it (in quotation marks) " "some information' out there, external to human beings but created by them."

- Authors from the objective side made also similar extension. Even insisting that information is in the physical world, some accept that human being can superimpose their order on the perceived external one and filter/modify it, producing some kind of subjective order or information.

Consequently, we are noticing that by extending their meanings and/or des-radicalizing their respective positions, some authors are initiating processes that might culminate in the integration of both positions. So, a systemic meaning of information an/or research efforts oriented to a Systemic Information Theory, could surely serve as a catalyst for the integration process. Meanwhile, let us draw some practical consequences from what we have done up to the present.

\section{Practical Consequences}

To complete the elaboration of a Peircean meaning of information it is necessary to draw some practical consequences from the conceptual definition we have been doing as well as from the short overview we made on a systemic meaning of information. These consequences could be the following:

1) With the systemic approach we outlined above, we can conclude that in the fields of information systems and informing sciences, information should be considered four-folded: subjective information should be considered as well as objective information, the informative empirical processes of sensations/perceptions and the actions taken on the information received, filtering/modifying it as a consequence of subjective filters, knowledge, emotions, feelings, attitudes, values, etc. The information systems development field takes into account mostly the software development side, i.e. the objective information processing, and does not care too much for the subjective information processing, let alone the perceptual phenomena and the subjective information filtering. University curricula should be extended/modified and development methodologies should be re-designed according these four folds of information. These four aspects should be integrated but never confused as it is usual to happen in academic courses and textbooks, as well as in methodological design and methodologies use in consulting, in the industry and in the corporative world. Most of all: Data should not be confused any more with information. Datum is the objective side and information is the subjective of a MIS/DSS/EIS. Even in the objective perspective data and information are completely different. Datum is the independent variable and Information is the dependent one. Information is minus logarithm of the probability of a given datum. Information is not formatted or organized data; information is not data in context as usually it is claimed in some IT circles and textbooks. Formatted data are formatted data, not information. Data in context is data in context, not information, by any means.

2) As we said above, data and Information are two sides of the same coin: the datum is the objective side of the information, and the information is the subjective side of the datum. Objective data are transformed to information by means of a subject's perception and interpretation. Electronic data processing in a Computerized Information Systems should be complemented by "biological data processing" in order to transform the data in information. Consequently, a computer supported IS should have an electronic data processing sub-system and a biological/human data processing system, adequately related to each other, in order to compose as a whole an IS. Consequently, analysis/synthesis activities should be done for both sub-systems, and not just, or mainly for the electronic processing, or the software development, side. Software users should also be "developed" and "maintained" accordingly. If not, we will be developing an electronic data processing system, or a "system for information," a system with the potential of producing information, but not an information System, in the sense that the system is producing and processing information. This is especially true in the case of MIS/DSS/EIS, where there is no doubt at all that we are talking about managerial information, i.e. human/subject information.

3) A datum might be informative or not informative. A datum with the potential of informing is an informative datum, and non-informative data have no potential information. My written name has no potential informa- 
tion for me if I find it in my passport, but it surely have a huge informative potential if I see it announced as a lottery winner. In the last case, my written name is - as Floridi (1999) would say - an answer to the question: did I win the lottery? Or who won the lottery? In the first case, my written name in the passport is not an answer to any question of mine, so it is not informative for me. But it sure is informative to the immigration agent. Consequently, we should distinguish among the concepts of data, informative data and information. They are definitely not the same: data are not the same as information, as an increasing number of authors (especially in the Informatics field) say explicitly and some others suggest implicitly. The web on-line Tech-Encyclopedia, for example, affirm that information is the "summarization of data. Technically, data are raw facts and figures that are processed into information, such as summaries and totals. But since information can also be raw data for the next job or person, the two terms cannot be precisely defined. Both terms are used synonymously and interchangeably" (TechEncyclopedia, 2000). It is true that both terms are being used synonymously and interchangeably, but this does not means that are synonymous. To use them as synonymous is to ab-use them. This theoretically incorrect and pragmatically dangerous. On the other hand, the Tech-Encyclopedia definition of information is incorrect and misleading: information is not summarization of data, nor summarization of data is information. "Summarization of data" is summarization of data. In the best case, it would be informative data, not information. To summarize a data might make it informative, if it is associated with an explicit or an implicit question made by the data receiver. A very important practical consequence we can draw here is: Informative systems are not the same as Information Systems. Informative Systems are part of Information Systems. What is usually referred in the literature as electronic information processing is, rigorously speaking, informative data processing. To develop information system, requires necessarily the development of an informative system, but this will not assure the development and use of the respective information system. The human part of the system should also be "developed" in order to assure the existence of the information system. This very important and necessary aspect for successful information systems development is lacking in university and industry courses, papers and books, as well as in the professional/corporative MIS development. This fact would explain most if the IS practical failures.
4) As we said above, the confusion between objective and subjective information processing is very dangerous, both: intellectually and pragmatically. Effective methodologies for software development in the NAS/MW realm are not necessarily effective in MIS/DSS/EIS development. Then, Information Technologies consultants, systems analysts, software development projects managers and university professors in software development should be aware, and make aware, about this homonymy in the term "information." Unfortunately this is that the case, in the present. The confusion exists, even in prestigious vendors, consultants and authors. It is not unusual to find university professors teaching MIS/DSS/EIS development by means of methodologies that are effective in the NAS/MW realm, but not necessarily effective in their subject matter. Technologies and methodologies used in effective NAS/MW development are necessary but not sufficient condition for MIS/DSS/EIS development. In these systems, information is subjective, or not just objective. So, the subject, i.e. the user, should also be "developed." In MIS/DSS/EIS there are two systems to be developed: an objective-information system and a subjective-information system. The existing confusion about the meaning of information might cause - and usually does cause - the development of just one of the required systems, i.e. the objectiveinformation system. The result of this is that the system developed is an informative system, not an information system, let alone an informing system. An informative system needs an informed user to be an information system. The process by which an informative system informs a user is an informing system. If we have no user prepared, "developed" in such a way as to enable the informative system to inform him, or her, we will have no information system, no informing process and no informing system. This is a very important conclusion, especially for information systems developers' education and training. They should be proficient in software development, which is a necessary condition, but it is not a sufficient one. They also should be proficient in what is required to assure the transformation of the data into information, or the transformation of objective-information into subjective-information. Otherwise they might fail in developing information systems, even if they develop high quality software.

5) The four points above show us how important is triviality for information systems and informing sciences students, professors, trainers, consultants, developers and projects managers. This assertion seems a nonsense and a joke. But, let us analyze the meaning of the 


\section{Toward a Systemic Notion of Information: Practical Consequences}

term in order to explain our assertion. To do so, it is good to analyze both: the actual semantic meaning of the word and its etymological sources.

a) In its usual meaning, triviality has a pejorative sense. It means the quality of being trivial, i.e. ordinary and commonplace. But, to be an effective information systems developer it is necessary to have a good communication, especially with the system users. This means that the information systems developer has to have a common language with them, which means, not just their business language (this fact is usually stressed in most courses and textbooks), but also the ordinary natural language used as a meta-language. Information systems technical jargon and computereese should be removed from the developer-user communication, because it is not common to both of them. Plain natural language, be it English, Spanish, or what ever is the users natural language, should be used; ordinary and commonplace words should be preferred. This not an easy thing to achieve, otherwise it would be no explanation why so many computer engineers and information systems developers fail at it. An adequate training should be provided, because it is not so trivial to be trivial, it is not easy for technical people to speak in a non-technical way, to be understood easily by non-technical people. Developers should be proficient in trivial natural language; they should manage their natural language as well as the artificial language used to program the computer. Otherwise, they are at risk of developing good software but a bad information system, a good objective-information system but a bad subjective-information system, a good informative system but a bad information system. This has been the case of many "well" managed software development projects, that end up with a high quality software, in time and in budget, but the software never was used, or just part of it went in use. The following reasoning also

b) contributed to this kind,, f failures

Etymologically, "trivial" derives from the Latin word trivialis, and this derives from trivium. This word was used in the Middle Ages to mean the group of three subjects, related to language teaching, which formed part of the curricula. The other four subjects taught formed the group named the quadrivium. The trivium meant the "three ways" to language, to its good and effective use. This three ways or subjects are: Grammar, Dialectic (in the sense of Dialogic) and Rhetoric. Grammar teaches to speak well. Dialogic provide the art of maintaining a useful dialogue, i.e. a competent communication. And Rhetoric provide the means of doing a pragmatically effective use of the language, i.e. obtaining the practical results sought by the use of the language. So many people knew the trivium in the Middle Ages that its three integrative subjects become a commonplace. Hence, emerged the word trivialis that means "trivial." And, here we have a bewildering paradox: what it was a common place in the Middle Age education is not so common, in out time, in professional activities that need most of it. Trivium is not trivial any more in our time, in the field of information systems where it is so needed and almost a necessary condition for effective professional activities. It is not being adequately taught in informing sciences and it not at all included in Computer Engineering or computerized Information Systems Engineering curricula. Trivium is so essential to an Information Systems Engineer performance as it is to a lawyer. Until Information Systems curricula designers do not understand this situation, the importance of solving its related problem and the real necessity of including in the respective curricula a trivium, adapted to our times and to the Informations Systems field, there will be no strong hope in increasing significantly the future professional effectiveness of the students.

\section{References}

Ackoff, R. (1962). Scientific Method: Optimizing Applied Research Decisions. New York: John Wiley and Sons.

Bar-Hillel Y. (1955). “An Examination of Information Theory”, Philosophy of Science, 22, pp. 86-101. Reprinted as Bar-Hillel (1964, pp. 275-97)

Bar-Hillel, Y. (1964). Language and Information: Selected Essays on their Theory and Applications. Adission-Wesley.

Boland,R. J. (1987). "The In-formation of Information Systems," in R. L. Boland and R.A. Hirschheim (eds.), Critical Issues In Information Systems Research. New York: John Wiley and Sons.

Checkland, P. B. and Scholes, J. (1990). Soft Systems Methodology in Action. New York: John Wiley and Sons.

Callaos, N. (1995a). "Significados de Definición” ("The Meanings of Definitions") in Metodología Sistémica de Sistemas (A Systemic Systems Methodology); Universidad Simón Bolívar, Caracas, Venezuela, Chapter 2.

Callaos, N. (1995b). "Metodologia Sistémica de Sistemas: Integración de la Macro-Estructura" ("A Systemic Systems Methodology: Macro-Structure Integration") in Metodología Sistémica de Sistemas (A Systemic Systems Methodology); Universidad Simón Bolívar, Caracas, Venezuela, Chapter 12. 


\section{Nagib Callaos and Belkis Callaos}

Churmann C. W. (1971). The Design of Enquiring Systems: Basic Concepts of Systems and Organization. New York: Basic Books, Inc. Pub.

Cover, T. M. and Thomas, J. A. (1991). Elements of Information Theory. New York: John Wiley \& Sons, Inc.

Cohen, E. B. (1997). "IS as an Evolving Field." Proceedings of the World Multi-Conference on Systemics, Cybernetics, and Informatics, Caracas, Venezuela, July 7-11, 1997, ed. by N. Callaos, C.M. Hoong, and E. Cohen.

Cohen, E. B. and Boyd E. C. (1999). "Introduction to Informing Science," Proceedings of the World Multi-Conference on Systemics, Cybernetics and Informatics, Vol. 8, pp 451-456; Orlando, Florida, July 31-August 4, 1999, ed. by M. Torres, B. Sanchez, and E. Wills.

Cohen, E. B. (2000) Reconceptualizing Information Systems as a Field of theTransdiscipline Informing Science: From Ugly Duckling to Swan, Journal of Computing and Information Technology. 7 (3) 1999, 213-219, retrieved Dec.17, 2000 from ittp:/inform.nu/Whatsis.htm.

Cherry C. (1978). On Human Communication. $3^{\text {rd }}$ edition. Cambridge, Mass.: MIT Press.

Copleston, F. (1985). A History of Philosophy. New York: Image Books, Doubleday

Dervin B. (1981). "Mass communicating: Changing Conceptions of the audience.” In R. E. Rice and W.J. Paisley (eds.) Public Communication Campaigns, pp.71-78. Beverly Hills, Calif.: Sage Publications.

Dervin B. (1983). "An overview of Sense-Making Research: Concepts, Methods and Results to Date" Presented at the International Communication Association Annual Meeting. Dallas, May. Seattle: School of Communications, University of Washington.

Dretske, F. (1981). Knowledge and the Flow of Information. Blakwell.
Floridi, L. (1999). Philosophy and Computing, An Introduction. London: Routledge, Taylor and Francis Group.

Hoad, T. F. (1993). The Concise Oxford Dictionary of English Etymology. Oxford: Oxford University Press.

Lewis, P. (1991). “The Decision Making Basis for Information Systems: The Contribution of Vickers' Concept of Appreciation to a Soft Systems Perspective", Journal of Information Systems, 1 (1), 3343.

Merriam-Webster's Collegiate Dictionary. (1999). Springfield, Mass: Merriam-Webster Inc. Third Edition.

Mingers, J. (1997). "The Nature of Information and Its Relationships to Meaning," in R.L. Winder, S. K. Probert and I. A. Besson, (eds), Philosophical Aspects of Information Systems. London: Taylor \& Francis, pp. 73-84.

Neill, S. D. (1992). Dilemmas in the Study of Information: Exploring the Boundaries of Information Science. New York: Greenwood Press.

Ogden, C. K. and Richard I. A. (1989). The Meaning of Meaning: A Study of the Influence of Language upon Thought and of the Science of Symbolism. Harcourt.

Peirce, C. S. (1931-5,1958). Collected Papers of Charles Sanders Peirce, 8 vols. Cambridge, Mass. Volumes I-VI, edited by C. Hartshorne and P. Weiss and first published 1931-5, have been re-issued in 1960 as three volumes. Volumes VII-VIII, edited by A. W. Burke, were published in 1958 .

Stonier, T. (1997). Information and Meaning: An Evolutionary Perspective. London: Springer.

Siegfried, T. (2000). The bit and the Pendulum. New York: John Wiley and Sons, Inc.

Tech-Encyclopedia (2000). Retrieved December $19^{\text {th }} .2000$ from World Wide Web:

http://www.techweb.com/encyclopedia/defineterm?term=informati on' 